Check for updates

Cite this: RSC Adv., 2019, 9, 8369

Received 7th February 2019

Accepted 6th March 2019

DOI: $10.1039 / c 9 r a 00995 g$

rsc.li/rsc-advances

\section{1-Alkyl-3-alkylindolin-2-imine hydrochlorides as useful building blocks in the copper-catalyzed synthesis of polycyclic indoline scaffolds $\uparrow$}

\author{
Can Liu, ${ }^{\text {ab }}$ Haijun Yang, ${ }^{\mathrm{b}}$ Changjin Zhu ${ }^{\mathrm{a}}$ and Hua Fu (D) *ab \\ A novel and efficient copper-catalyzed synthesis of dihydro-6H-indolo[2,3-b]quinoline derivatives has been \\ developed by using 3-alkyl-1-alkylindolin-2-imine hydrochlorides as the building blocks. Furthermore, easy \\ reduction of dihydro-6H-indolo[2,3-b]quinolines with diisobutylaluminum hydride provided tetrahydro- \\ $6 \mathrm{H}$-indolo[2,3-b]quinoline derivatives in excellent yields. The present method shows some advantages \\ including use of cheap cuprous chloride as the catalyst and tolerance of wide functional groups.
}

Indole alkaloids widely occur in nature and exhibit diverse and interesting biological and pharmacological activities. ${ }^{1}$ For example, perophoramidine (A) and communesins (B-I), isolated from Penicillium species, ${ }^{2}$ a marine fungal strain, and Philippine ascidian Perophora namei,,$^{3}$ show important cytotoxicity and insecticidal properties (Fig. 1). Both intriguing structural complexity and interesting biological activities of these alkaloids attract much attention for organic synthetic chemists. ${ }^{4}$
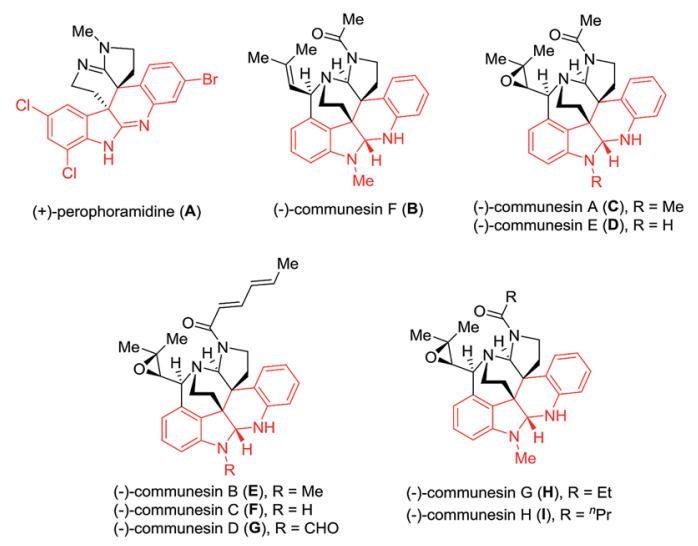

Fig. 1 Structures of representative perophoramidine and communesin alkaloids with diverse biological activities.

${ }^{a}$ School of Chemistry and Chemical Engineering, Beijing Institute of Technology, Beijing 100081, P. R. China. E-mail: fuhua@mail.tsinghua.edu.cn; Fax: +86 10 62781695

${ }^{b}$ Key Laboratory of Bioorganic Phosphorus Chemistry and Chemical Biology (Ministry of Education), Department of Chemistry, Tsinghua University, Beijing 100084, P. R. China

$\dagger$ Electronic supplementary information (ESI) available: Synthetic procedures, characterization data and ${ }^{1} \mathrm{H},{ }^{13} \mathrm{C},{ }^{19} \mathrm{~F}$ NMR spectra of these synthesized compounds. See DOI: 10.1039/c9ra00995g
In previous synthesis of indole alkaloids, dearomatization of readily available indoles is often used in the construction of complex indole-containing structural motifs. ${ }^{5}$ In particular, dearomatizing C3-alkylation/arylation of 3-substituted indoles first provides C3-quaternary indolenines, and then the indolenines are used as the versatile building blocks for the synthesis of complex indole alkaloids and related compounds. ${ }^{6}$ However, this strategy often needs long multi-step and tedious processes. As an alternative, dearomatizing alkylation of tryptamine derivatives yields the C3-quaternary indolenines followed spontaneous cyclization to afford pyrroloindolines (Scheme 1a). ${ }^{7}$ To the best of our knowledge, 1-alkyl-3-alkylindolin-2imine hydrochlorides as a kind of indole derivatives have not been used in synthesis of indole alkaloids thus far. Herein, we report application of 1-alkyl-3-alkylindolin-2-imine hydrochlorides as the useful building blocks in copper-catalyzed synthesis of polycyclic indoline scaffolds (Scheme 1b).

At the outset, copper-catalyzed reaction of 3-benzyl-1methylindolin-2-imine hydrochloride (1h) with 2-iodobenzyl bromide (2a) leading to 10b-benzyl-6-methyl-10b,11-dihydro$6 H$-indolo[2,3-b]quinoline $(3 \mathbf{h})$ was selected as the model to optimize conditions including catalysts, base, solvents and temperature. As shown in Table 1, six catalysts, $\mathrm{CuI}, \mathrm{CuBr}, \mathrm{CuCl}$,

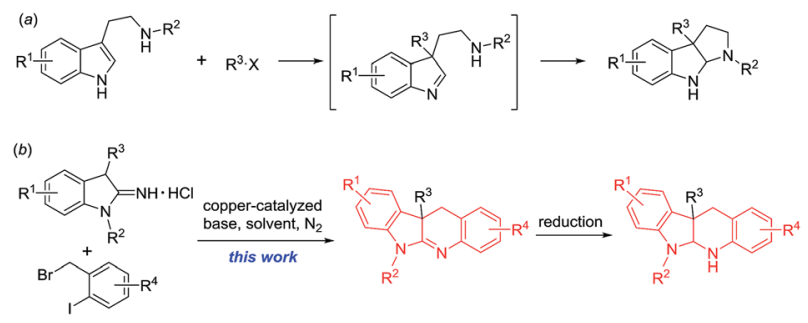

Scheme 1 Synthesis of polycyclic indoline scaffolds using tryptamine derivatives (a) or 1-alkyl-3-alkylindolin-2-imine hydrochlorides (b) as the useful building blocks. 
Table 1 Optimization of conditions for copper-catalyzed reaction of 3-benzyl-1-methylindolin-2-imine hydrochloride (1h) with 2-iodobenzyl bromide (2a) leading to 10b-benzyl-6-methyl-10b,11-dihydro$6 \mathrm{H}$-indolo[2,3-b]quinoline $(3 h)^{a}$

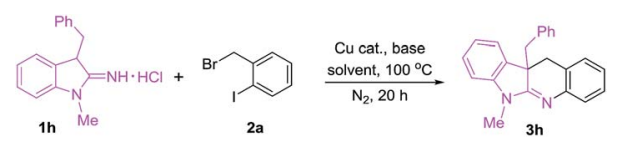

\begin{tabular}{lllll}
\hline Entry & Cat. & Base & Solvent & Yield $^{b}(\%)$ \\
\hline 1 & $\mathrm{CuI}$ & ${ }^{t} \mathrm{BuONa}$ & ${ }^{t} \mathrm{BuOH}$ & 73 \\
2 & $\mathrm{CuBr}$ & ${ }^{t} \mathrm{BuONa}$ & ${ }^{t} \mathrm{BuOH}$ & 78 \\
3 & $\mathrm{CuCl}$ & ${ }^{t} \mathrm{BuONa}$ & ${ }^{t} \mathrm{BuOH}$ & 90 \\
4 & $\mathrm{Cu}_{2} \mathrm{O}$ & ${ }^{t} \mathrm{BuONa}$ & ${ }^{t} \mathrm{BuOH}$ & 75 \\
5 & $\mathrm{Cu}(\mathrm{OAc})_{2}$ & ${ }^{t} \mathrm{BuONa}$ & ${ }^{t} \mathrm{BuOH}$ & 83 \\
6 & $\mathrm{Cu}(\mathrm{TFA})_{2}$ & ${ }^{t} \mathrm{BuONa}$ & ${ }^{t} \mathrm{BuOH}$ & 81 \\
7 & $\mathrm{CuCl}$ & ${ }^{t} \mathrm{BuONa}$ & ${ }^{\mathrm{CH}}{ }_{3} \mathrm{CN}$ & 46 \\
8 & $\mathrm{CuCl}$ & ${ }^{t} \mathrm{BuONa}^{\mathrm{i}} \mathrm{PrOH}$ & 81 \\
9 & $\mathrm{CuCl}$ & ${ }^{t} \mathrm{BuONa}$ & ${ }^{\mathrm{T}} \mathrm{Oluene}$ & 42 \\
10 & $\mathrm{CuCl}$ & ${ }^{t} \mathrm{BuONa}$ & $1,4-\mathrm{Dioxane}$ & 38 \\
11 & $\mathrm{CuCl}$ & ${ }^{t} \mathrm{BuOLi}^{t} \mathrm{BuOH}$ & 89 \\
$\mathbf{1 2}$ & $\mathrm{CuCl}$ & $\mathrm{K}_{2} \mathrm{CO}_{3}$ & ${ }^{t} \mathrm{BuOH}$ & 91 \\
13 & $\mathrm{CuCl}$ & $\mathrm{Cs}_{2} \mathrm{CO}_{3}$ & ${ }^{t} \mathrm{BuOH}$ & 88 \\
14 & $\mathrm{CuCl}$ & $\mathrm{K}_{3} \mathrm{PO}_{4}$ & ${ }^{t} \mathrm{BuOH}$ & 86 \\
15 & $\mathrm{CuCl}$ & $\mathrm{NaOAc}^{t} \mathrm{BuOH}$ & 43 \\
16 & $\mathrm{CuCl}$ & ${ }^{t} \mathrm{DIPEA}$ & ${ }^{t} \mathrm{BuOH}$ & Trace \\
$17^{c}$ & $\mathrm{CuCl}$ & $\mathrm{K}_{2} \mathrm{CO}_{3}$ & ${ }^{t} \mathrm{BuOH}$ & 80 \\
$18^{d}$ & $\mathrm{CuCl}$ & $\mathrm{K}_{2} \mathrm{CO}_{3}$ & ${ }^{t} \mathrm{BuOH}$ & 91
\end{tabular}

${ }^{a}$ Reaction conditions: under nitrogen atmosphere, 3-benzyl-1methylindolin-2-imine hydrochloride (1h) (0.33 mmol, 1.1 equiv.), 2iodobenzyl bromide (2a) $(0.3 \mathrm{mmol}, 1.0$ equiv.), catalyst $(30 \mu \mathrm{mol}$, $10 \mathrm{~mol} \%)$, base $(1.2 \mathrm{mmol}, 4.0$ equiv.), solvent $(3.0 \mathrm{~mL})$, temperature $\left(100{ }^{\circ} \mathrm{C}\right)$, time $(20 \mathrm{~h})$ in a sealed Schlenk tube. ${ }^{b}$ Isolated yield. ${ }^{c}$ Temperature $\left(80^{\circ} \mathrm{C}\right) .{ }^{d}$ Temperature $\left(120^{\circ} \mathrm{C}\right)$.

$\mathrm{Cu}_{2} \mathrm{O}, \mathrm{Cu}(\mathrm{OAc})_{2}$ and $\mathrm{Cu}(\mathrm{TFA})_{2}$, were tested using $\mathrm{NaOBu}^{t}$ as the base and $\mathrm{HOBu}^{t}$ as the solvent under nitrogen atmosphere at $100{ }^{\circ} \mathrm{C}$ for $20 \mathrm{~h}$ (entries 1-6), and $\mathrm{CuCl}$ gave the highest yield (90\%) (entry 3). Subsequently, other four solvents, MeCN, $\mathrm{HOPr}^{\mathrm{i}}$, toluene and 1,4-dioxane, were attempted (entries 7-10), and they were inferior to $\mathrm{HOBu}^{t}$ (compare entries 3, 7-10). Next, effect of bases including $\mathrm{LiOBu}^{t}, \mathrm{~K}_{2} \mathrm{CO}_{3}, \mathrm{Cs}_{2} \mathrm{CO}_{3}, \mathrm{~K}_{3} \mathrm{PO}_{4}, \mathrm{NaOAc}$ and diisopropylethylamine (DIPEA) was investigated (entries 11-16), and the results showed that $\mathrm{K}_{2} \mathrm{CO}_{3}$ was a suitable base (entry 12). Finally, we attempted variation of temperature and found that $100{ }^{\circ} \mathrm{C}$ was an optimal temperature (compare entries 12, 17 and 18). Therefore, the copper-catalyzed optimal conditions for synthesis of 10b-benzyl-6-methyl-10b,11-dihydro- $6 H^{-}$ indolo[2,3-b]quinoline are as follows: $10 \mathrm{~mol} \% \mathrm{CuCl}$ as the catalyst, $\mathrm{K}_{2} \mathrm{CO}_{3}$ as the base, and $\mathrm{HOBu}^{t}$ as the solvent under nitrogen atmosphere at $100{ }^{\circ} \mathrm{C}$ for $20 \mathrm{~h}$.

After obtaining the optimized conditions, we surveyed substrate scope for the copper-catalyzed reactions of 1-alkyl-3alkylindolin-2-imine hydrochlorides (1) with substituted 2iodobenzyl bromides (2) leading to dihydro- $6 \mathrm{H}$-indolo[2,3- $b$ ] quinolines (3). As shown in Table 2, we first surveyed reactivity of substrates (1) using 2-iodobenzyl bromide (2a) as the partner. When substituents $R^{3}$ in $\mathbf{1}$ were aliphatic alkyls (see $\mathbf{3 a}-\mathbf{3 e}$ ), substituted benzyls (see $\mathbf{3 f}-\mathbf{3 l}$ ), substituted phenylethyls (see 3m-3o), phenylpropyl (see 3p) and phenyl (see 3q), and the reactions were performed well. Subsequently, variation of substituent groups $\mathrm{R}^{2}$ including ethyl (see $3 \mathbf{r}$ ), propyl (see $3 \mathbf{s}$ ), butyl (see 3t), allyl (see 3u), benzyl (see 3v) and phenylpropyl (see $3 \mathbf{w})$ in $\mathbf{1}$ was investigated, and the substrates provided the corresponding target products $(\mathbf{3 r}-\mathbf{3} \mathbf{w})$ in $82-92 \%$. Next, several substrates 1 containing different $\mathrm{R}^{1}$ substituents including electron-donating (see 3x-3ab), poor electron-withdrawing (see 3ac-3ae), strong electron-withdrawing (see 3af-3ah) groups

Table 2 Substrate scope for copper-catalyzed synthesis of dihydro$6 \mathrm{H}$-indolo[2,3-b]quinolines $(3)^{a}$

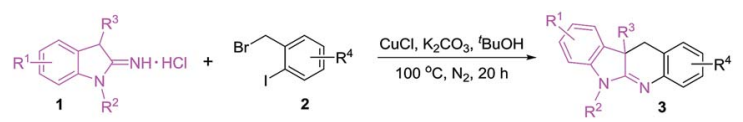

3 (time, yield $^{b}$ )
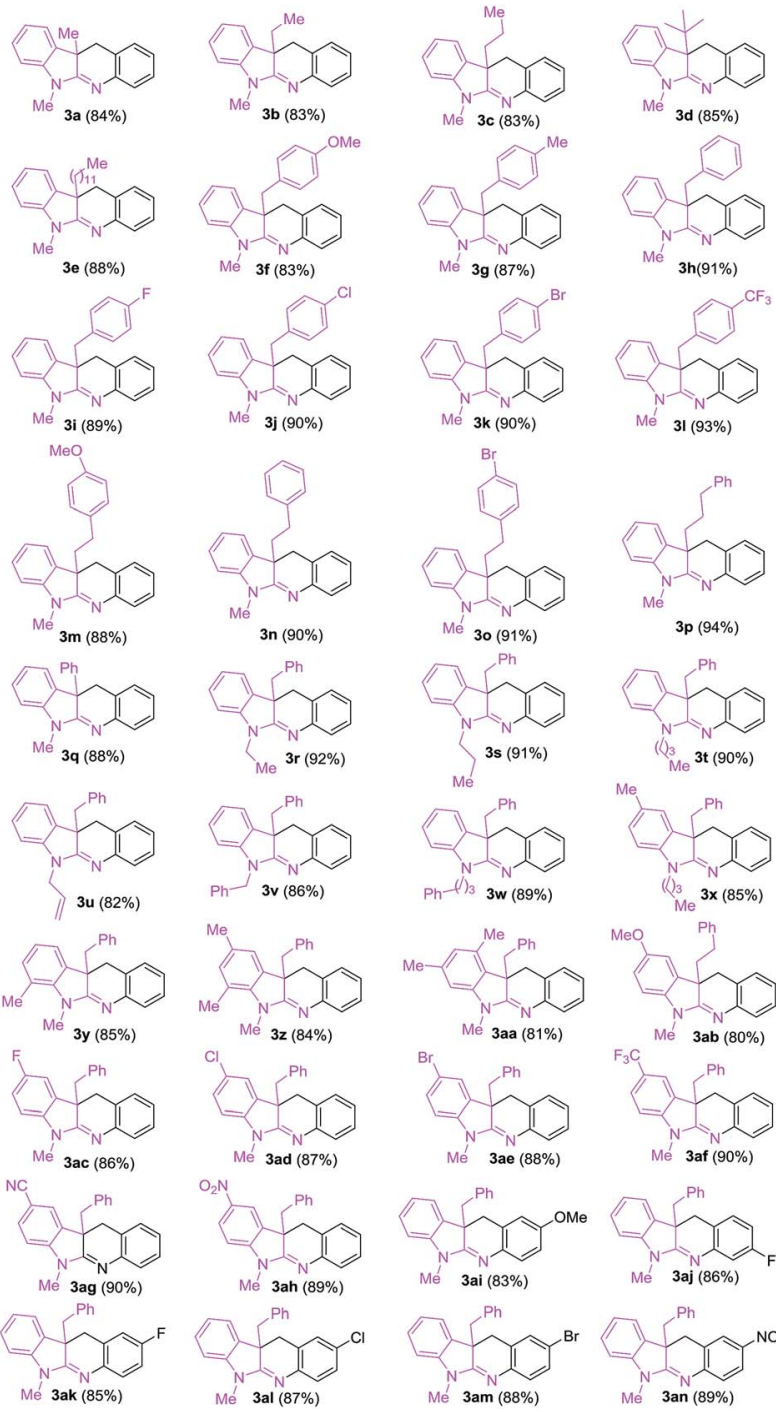

Mé

3 n $(90 \%)$

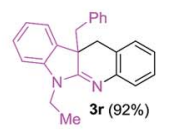

Mé $30(91 \%)$

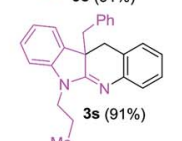

$3 p(94 \%)$
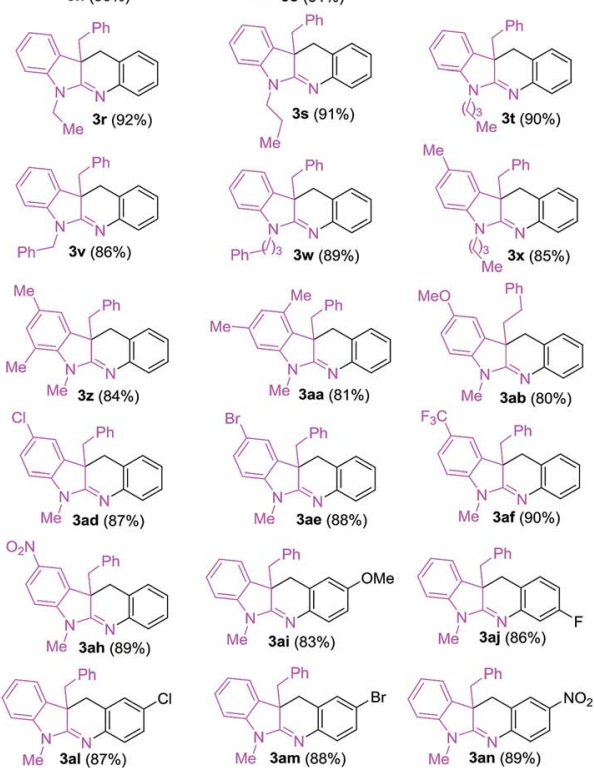

${ }^{a}$ Reaction conditions: under nitrogen atmosphere, 3-alkyl-1alkylindolin-2-imine hydrochloride (1) (0.33 mmol, 1.1 equiv.), substituted 2 -iodobenzyl bromide (2) (0.3 mmol, 1.0 equiv.), $\mathrm{CuCl}(30$ $\mu \mathrm{mol}, 10 \mathrm{~mol} \%), \mathrm{K}_{2} \mathrm{CO}_{3}\left(1.2 \mathrm{mmol}, 4.0\right.$ equiv.), ${ }^{t} \mathrm{BuOH}(3.0 \mathrm{~mL})$, temperature $\left(100{ }^{\circ} \mathrm{C}\right)$, time $(20 \mathrm{~h})$ in a sealed Schlenk tube. ${ }^{b}$ Isolated yield. 
were tested, and they afforded $3 \mathbf{x}-3 \mathbf{a h}$ in $80-90 \%$. Finally, several substituted 2-iodobenzyl bromide (2) were applied with 3-benzyl-1-methylindolin-2-imine hydrochloride (1h) as the partner, and the target products (3ai-3an) were obtained in high yields. The copper-catalyzed reactions showed tolerance of various functional groups including $\mathrm{C}-\mathrm{F}$ (see 3i, 3ac, 3aj and 3ak), C-Cl (see 3j, 3ad and 3al), C-Br (see 3k, 3o, 3ae and 3am) bonds, ether (see 3f, 3m, 3ab and 3ai), trifluoromethyl (see $3 \mathbf{l}$ and 3af), cyano (see 3ag) and nitro (see 3ah and 3an) groups.

To explore mechanism on the copper-catalyzed reactions of 1 with 2, two control experiments were carried out as follows: (a) reaction of 3-benzyl-1-methylindolin-2-imine hydrochloride (1h) with 2-iodobenzyl bromide (2a) produced 4 in 95\% yield in the absence of copper catalyst at room temperature (Scheme 2a). (b) Copper-catalyzed intramolecular $N$-arylation of 4 gave the target product $(\mathbf{3 h})$ in $93 \%$ yield under the standard conditions (Scheme 2b). According to the results above, the copper-catalyzed reaction mechanism is proposed in Scheme $3 .^{\mathbf{8}}$ First, 1 transforms into anion $\mathbf{I}$ in the presence of base $\left(\mathrm{K}_{2} \mathrm{CO}_{3}\right)$, and nucleophilic attack of $\mathbf{I}$ to 2 yields II. Coordination of $\mathrm{CuCl}$ with nitrogen in imine group of II provides III, and oxidative addition of III forms IV in the presence of base. Finally, reductive elimination of $\mathbf{I V}$ gives the target product (3) freeing copper catalyst.

Furthermore, easy reduction of dihydro- $6 H$-indolo[2,3- $b]$ quinolines (3) with diisobutylaluminum hydride (DIBAL-H) in toluene at $0{ }^{\circ} \mathrm{C}$ led to another kind of N-heterocycles, tetrahydro-6 $H$-indolo $[2,3-b]$ quinolines $(\mathbf{5 a}-\mathbf{5 f})$ with wide biological activities $^{2,3}$ (Scheme 4). However, the traditional methods for

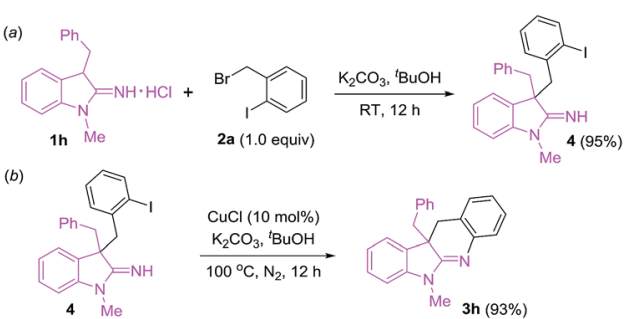

Scheme 2 (a) Reaction of 3-benzyl-1-methylindolin-2-imine hydrochloride (1g) with 2-iodobenzyl bromide (2a) in the absence of copper catalyst leading to 4 . (b) Copper-catalyzed intramolecular cyclization of 4 under the standard conditions.

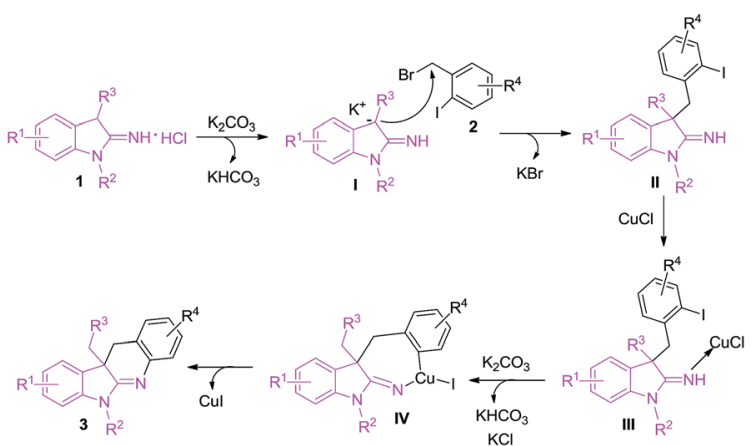

Scheme 3 Reaction mechanism for the copper-catalyzed synthesis of dihydro-6H-indolo[2,3-b]quinolines (3).

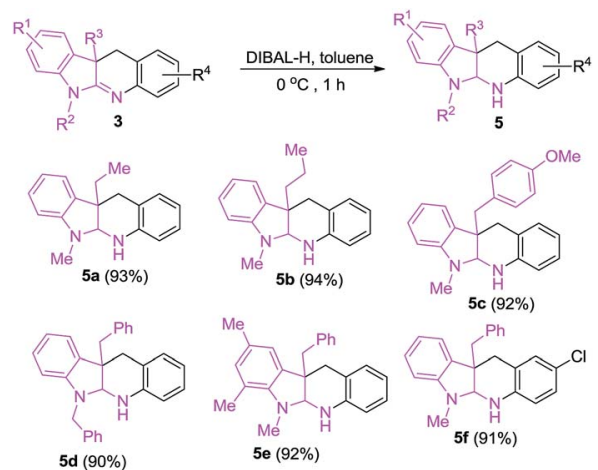

Scheme 4 Reduction of dihydro-6H-indolo[2,3-b]quinolines (3) with DIBAL-H leading to tetrahydro- $6 \mathrm{H}$-indolo[2,3-b]quinolines (5).

synthesis of this kind of compounds need long multi-step processes by using common indoles as the starting materials. Therefore, the present method using 3-alkyl-1-alkylindolin-2imine hydrochlorides as the building blocks is very simple and practical strategy for construction of dihydro- $6 \mathrm{H}$-indolo[2,3$b]$ quinoline and tetrahydro- $6 H$-indolo[2,3- $b]$ quinoline derivatives.

In summary, we have developed a novel and efficient coppercatalyzed synthesis of dihydro- $6 \mathrm{H}$-indolo[2,3- $b]$ quinoline derivatives by using 3-alkyl-1-alkylindolin-2-imine hydrochlorides as the building blocks. Furthermore, easy reduction of dihydro$6 H$-indolo[2,3- $b]$ quinolines with DIBAL-H provided tetrahydro$6 H$-indolo[2,3- $b]$ quinolines. The present method shows some advantages including use of cheap $\mathrm{CuCl}$ as the catalyst, and tolerance of wide functional groups. We believe that 3-alkyl-1alkylindolin-2-imine hydrochlorides as the building blocks will find wide application in synthesis of complex polycyclic indoline scaffolds.

\section{Conflicts of interest}

There are no conflicts to declare.

\section{Acknowledgements}

We thank the National Natural Science Foundation of China (Grant No. 21772108) for financial support.

\section{Notes and references}

1 (a) U. Anthoni, C. Christophersen and P. H. Nielsen, in Alkaloids: Chemical and Biological Perspectives, ed. S. W.Pelletier, Wiley, New York, 1999, vol. 13, p. 163; (b) H. L. Pearce, in The Alkaloids, ed. A.Brossi and M.Suffness, Academic, San Diego, CA, 1990, vol. 37, p. 145.

2 (a) P. W. Dalsgaard, J. W. Blunt, M. H. G. Munro, J. C. Frisvad and C. Christophersen, J. Nat. Prod., 2005, 68, 258; (b) B. Andersen, J. Smedsgaard and J. C. Frisvad, J. Agric. Food Chem., 2004, 52, 2421; (c) H. Hayashi, H. Matsumoto and K. Akiyama, Biosci., Biotechnol., Biochem., 2004, 68, 753; (d) R. Jadulco, R. A. Edrada, R. Ebel, A. Berg, K. Schaumann, V. Wray, K. Steube and P. Proksch, J. Nat. Prod., 2004, 67, 
78; (e) A. Numata, C. Takahashi, Y. Ito, T. Takada, K. Kawai, Y. Usami, E. Matsumura, M. Imachi, T. Ito and T. Hasegawa, Tetrahedron Lett., 1993, 34, 2355.

3 S. M. Verbitski, C. L. Mayne, R. A. Davis, G. P. Concepcion and C. M. Ireland, J. Org. Chem., 2002, 67, 7124.

4 For a recent review, see: $(a)$ B. M. Trost and M. Osipov, Chem. -Eur. J., 2015, 21, 16318; For selected papers, see: (b) J. Yang, H. Wu, Y. Shen and Y. Qin, J. Am. Chem. Soc., 2007, 129, 13794; (c) P. Liu, J. H. Seo and S. M. Weinreb, Angew. Chem., Int. Ed., 2010, 49, 2000; (d) J. H. Seo, G. D. Artman III and S. M. Weinreb, J. Org. Chem., 2006, 71, 8891; (e) J. Belmar and R. L. Funk, J. Am. Chem. Soc., 2012, 134, 16941; (f) J. R. Fuchs and R. L. Funk, J. Am. Chem. Soc., 2004, 126, 5068; (g) S.-J. Han, F. Vogt, S. Krishnan, J. A. May, M. Gatti, S. C. Virgil and B. M. Stoltz, Org. Lett., 2014, 16, 3316; (h) S.-J. Han, F. Vogt, J. A. May, S. Krishnan, M. Gatti, S. C. Virgil and B. M. Stoltz, J. Org. Chem., 2015, 80, 528; (i) Z. Zuo, W. Xie and D. Ma, J. Am. Chem. Soc., 2010, 132, 13226; (j) Z. Zuo and D. Ma, Angew. Chem., Int. Ed., 2011, 50, 12008; (k) A. Sabahi, A. Novikov and J. D. Rainier, Angew. Chem., Int. Ed., 2006, 45, 4317.

5 For reviews of dearomatization reactions, see: (a) S. P. Roche and J. A. Porco Jr, Angew. Chem., Int. Ed., 2011, 50, 4068; (b) C.-X. Zhuo, W. Zhang and S.-L. You, Angew. Chem., Int. Ed., 2012, 51, 12662.
6 For selected examples, see: (a) R. Robinson and H. Suginome, J. Chem. Soc., 1932, 298; (b) R. B. Woodward, M. P. Cava, W. D. Ollis, A. Hunger, H. U. Daeniker and K. Schenker, J. Am. Chem. Soc., 1954, 76, 4749; (c) G. Stork and J. E. Dolfini, J. Am. Chem. Soc., 1963, 85, 2872; (d) F. He, Y. Bo, J. D. Altom and E. J. Corey, J. Am. Chem. Soc., 1999, 121, 6771; (e) S. A. Kozmin, T. Iwama, Y. Huang and V. H. Rawal, J. Am. Chem. Soc., 2002, 124, 4628.

7 For a recent review, see: (a) P. Ruiz-Sanchis, S. A. Savina, F. Albericio and M. Álvarez, Chem.-Eur. J., 2011, 17, 1388; For selected papers, see: $(b)$ M. Kawahara, A. Nishida and M. Nakagawa, Org. Lett., 2000, 2, 675; (c) G. H. Tan, X. Zhu and A. Ganesan, Org. Lett., 2003, 5, 1801; (d) J. F. Austin, S.-G. Kim, C. J. Sinz, W.-J. Xiao and D. W. C. MacMillan, Proc. Natl. Acad. Sci. U. S. A., 2004, 101, 5482.

8 For selected reviews on copper-catalyzed reactions, see: $(a)$ S. V. Ley and A. W. Thomas, Angew. Chem., Int. Ed., 2003, 42, 5400; (b) I. P. Beletskaya and A. V. Cheprakov, Coord. Chem. Rev., 2004, 248, 2337; (c) G. Evano, N. Blanchard and M. Toumi, Chem. Rev., 2008, 108, 3054; (d) D. Ma and Q. Cai, Acc. Chem. Res., 2008, 41, 1450; (e) F. Monnier and M. Taillefer, Angew. Chem., Int. Ed., 2009, 48, 6954; (f) D. S. Surry and S. L. Buchwald, Chem. Sci., 2010, 1, 13; $(g)$ H. Rao and H. Fu, Synlett, 2011, 745; (h) T. Liu and H. Fu, Synthesis, 2012, 44, 2805 and references cited therein. 